\title{
ESTIMAÇÃO DOS COMPONENTES DA VARIÂNCIA FENOTÍPICA EM FĖIJOEIRO UTILIZANDO O MÉTODO GENEALÓGICO
}

\author{
Estimation of phenotypic variance components in common bean by the pedigree method
}

\author{
Alexsander Luís Moretoํ, Magno Antonio Patto Ramalho², José Airton Rodrigues Nunes ${ }^{3}$, \\ Ângela de Fátima Barbosa Abreu ${ }^{4}$
}

\begin{abstract}
RESUMO
A obtenção de informações a respeito do controle genético dos caracteres por meio de variâncias com associação aos métodos de condução de populações de feijoeiro tem sido uma estratégia pouco empregada, porém pode ser de grande auxílio aos melhoristas na tomada de decisões. Com esse objetivo foi utilizada uma população segregante proveniente do cruzamento entre as cultivares BRS MG Talismã e BRS Valente. $\mathrm{O}$ avanço das gerações foi realizado de acordo com o preconizado pelo método genealógico. Em $\mathrm{F}_{4 \cdot 5}$ obtiveram-se 256 progênies que foram avaliadas na safra 'das águas'2004/2005. As sementes de cada progênie foram colhidas em bulk originando as progênies $\mathrm{F}_{4: 6}$, as quais foram avaliadas na safra 'das secas' 2005. Os caracteres avaliados foram produtividade de grãos e porte das plantas. Constatou-se que na produção de grãos por planta, a variância ambiental dentro da parcela foi o principal componente da variância fenotípica entre progênies. A variância genética aditiva foi predominante para a produção de grãos, enquanto que para o porte a variância genética de dominância foi expressiva.
\end{abstract}

Termos para indexação: Phaseolus vulgaris, componentes de variância, método genealógico.

\section{ABSTRACT}

Obtaining information referent to the genetic control of traits by the estimates of variance associated to breeding methods is not frequently used for bean crops, however these estimate can greatly help breeders to take decision. With this objective a segregating population derived from a cross between the cultivars BRS MG Talismã and BRS Valente was evaluated. The advance of generations was done according to the pedigree method. In the $\mathrm{F}_{4 \cdot 5}$ generation were obtained 256 progenies that were evaluated during the 2004/ 2005 'rain season'. Seeds were harvested in bulks, generating progenies $\mathrm{F}_{4: 6}$, which were evaluated in the 2005 'dry season'. There evaluated grain yield and plant habit. For grain yield per plant, the environmental variance within plots was the main component of the phenotypic variance among progenies. The additive variance was predominant for grain yield and the dominance variance for plant habit.

Index terms: Phaseolus vulgaris, components of variance, pedigree method.

(Recebido em 9 de março de 2006 e aprovado em 30 de agosto de 2006)

\section{INTRODUÇÃO}

A obtenção de informações a respeito do controle genético dos caracteres auxilia os melhoristas na tomada de decisão. No caso dos caracteres quantitativos, essas informações podem ser obtidas utilizando componentes de média ou de variância (CRUZ et al., 2004). Os componentes da variância têm a vantagem de os efeitos genéticos não se anularem, como pode ocorrer com médias, e possibilitam também estimar a herdabilidade e o ganho esperado com a seleção.

Há, na literatura, algumas informações sobre o controle genético de alguns caracteres do feijoeiro utilizando variâncias, sendo a maioria com a geração $\mathrm{F}_{2} \mathrm{e}$ retrocruzamentos (TEIXEIRA et al., 1999) e cruzamentos dialélicos (OTUBO et al., 1995; SANTOS, 1984). O ideal, contudo, é associar o programa de melhoramento com a obtenção de estimativas que auxiliem os melhoristas na tomada de decisões. Essa estratégia tem sido relativamente pouco empregada com a cultura do feijoeiro. Além do mais, a maioria dos trabalhos existentes utilizaram o método denominado de progênies derivadas de plantas $\mathrm{F}_{2}$ (SOUZA \& RAMALHO, 1995). A desvantagem desse procedimento é que as progênies são avaliadas em gerações diferentes, o que dificulta as estimativas dos componentes de média ou variância devido ao efeito da interação genótipos por ambientes. Acrescenta-se ainda que o coeficiente associado

1'Doutorando em Genética e Melhoramento de Plantas no Departamento de Biologia/DBI - Universidade Federal de Lavras/UFLA - Cx. P. 3037 37200-000 - Lavras, MG - almoreto@yahoo.com.br

2Dr. em Genética e Melhoramento de Plantas - Professor Titular do Departamento de Biologia/DBI - Universidade Federal de Lavras/UFLA - Cx. P. 3037 37200-000 - Lavras, MG - magnoapr@ufla.br

${ }^{3}$ Dr. em Genética e Melhoramento de Plantas - Professor Assistente do Departamento de Planejamento/DPPA - Centro de Ciências Agrárias/CCA Universidade Federal do Piauí/UFPI - 64056-550 - Teresina, PI - jarnunes@ufpi.br

${ }^{4}$ Dra. em Genética e Melhoramento de Plantas - Pesquisadora EMBRAPA Arroz e feijão - Departamento de Biologia da Universidade Federal de Lavras/UFLA - Cx. P. 3037 - 37200-000 - Lavras, MG - afbabreu@ufla.br 
à variância aditiva é sempre um; devido a isso, qualquer flutuação nos valores obtidos reflete na estimativa da variância de dominância.

A utilização de progênies no método genealógico tem a vantagem de, devido à hierarquia das progênies, apresentar várias equações simultaneamente, o que deve melhorar a confiabilidade das estimativas obtidas. Não foi encontrado nenhum relato da utilização desse método na obtenção das estimativas dos parâmetros genéticos para a cultura do feijoeiro. Dessa forma, esse trabalho foi realizado com o objetivo de estimar componentes da variância fenotípica empregando o método genealógico de condução de populações segregantes para alguns caracteres da cultura do feijoeiro.

\section{MATERIAL E MÉTODOS}

Os experimentos foram conduzidos na área experimental do Departamento de Biologia da Universidade Federal de Lavras (UFLA), no município de Lavras, Estado de Minas Gerais, situado a 918 metros de altitude, $21^{\circ} 14^{\prime}$ S de latitude e $45^{\circ} 00^{\prime} \mathrm{W}$ de longitude. Os genitores utilizados na obtenção da população segregante foram as cultivares BRS MG Talismã de grão tipo carioca e hábito de crescimento tipo III e BRS Valente de grão preto e hábito de crescimento tipo II.

Os cruzamentos foram realizados em casa-devegetação. A geração $F_{2}$ foi obtida sob condição de campo sendo colhidas aleatoriamente 64 plantas, as quais originaram as progênies $\mathrm{F}_{2: 3}$. As mesmas foram semeadas em parcelas de uma linha de um metro. De cada progênie $\mathrm{F}_{2: 3}$ foram tomadas duas plantas individualmente, que deram origem a 128 progênies $\mathrm{F}_{3: 4}$ e posteriormente foram colhidas 256 progênies $\mathrm{F}_{4: 5}$.

As progênies da geração $F_{4: 5}$ foram avaliadas na safra 'das águas'- (2004/2005), utilizando o delineamento látice simples 16 x 16. Cada parcela foi constituída por uma linha de um metro de comprimento com 15 sementes. $\mathrm{O}$ experimento foi instalado sob área de plantio direto e a adubação de plantio foi equivalente a $300 \mathrm{~kg} / \mathrm{ha}$ do formulado 8-28-16 de N, $\mathrm{P}_{2} \mathrm{O}_{5}$ e $\mathrm{K}_{2} \mathrm{O}$, aplicando $150 \mathrm{~kg} / \mathrm{ha}$ de sulfato de amônio em cobertura.

Foram avaliadas as características produção de grãos em gramas por parcela e porte das plantas por meio de uma escala de notas (COLLICCHIO et al., 1997), em que a nota 1 refere-se à planta de hábito II, ereta, com uma haste e com inserção alta das primeiras vagens; a nota 2, à planta de hábito II, ereta e com algumas ramificações; a nota 3, à planta de hábito II ou III, ereta e com muitas ramificações e tendência a prostrar-se; a nota 4 , à planta de hábito III, semi-ereta e mediamente prostrada; e a nota 5, à planta de hábito III, com entrenós longos e muito prostrada. Para produção de grãos colheu-se individualmente dez porcento das parcelas, para obtenção da produção por planta sendo o restante colhido misturando as mesmas.

Amostras das sementes colhidas da etapa anterior originaram as progênies $\mathrm{F}_{4: 6}$. Estas foram novamente avaliadas na safra 'das secas'; semeadura em fevereiro de 2005. Utilizou-se o mesmo procedimento anterior, exceto que as parcelas foram constituídas por 1 linha de dois metros de comprimento.

Os dados relativos à produção de grãos e notas de porte, em cada geração, foram submetidos à análise de variância, considerando todos os efeitos do modelo como aleatório, exceto a média. Posteriormente foi feita a análise conjunta das gerações $\mathrm{F}_{4: 5}$ e $\mathrm{F}_{4: 6}$ para ambos os caracteres avaliados. A variância fenotípica dentro das parcelas para geração $f\left(\sigma_{d_{f}}^{2}\right)$, foi obtida utilizando os dados de produção de grãos por planta de $10 \%$ das parcelas. A estimativa de $\sigma_{\mathrm{d}_{\mathrm{f}}}^{2}$ foi a média ponderada das variâncias fenotípicas por parcela.

As variâncias genéticas e fenotípicas entre progênies e os respectivos intervalos de confiança (IC) foram estimados utilizando as expressões apresentas por Ramalho et al. (2005). A herdabilidade no sentido amplo para a seleção na média das progênies na geração $f\left(h_{f}^{2}\right)$ foi estimada utilizando procedimento semelhante ao apresentado por Ramalho et al. (1993). Os intervalos de confiança de $h_{f}^{2}$ foram estimados segundo Knapp et al. (1985).

Para obtenção das estimativas dos componentes de variâncias genéticas e ambientais foram utilizadas as variâncias fenotípicas médias de progênies desconsiderando a interação gerações x progênies. A variância genética foi decomposta em função da covariância genética entre parentes utilizando o procedimento semelhante ao apresentado por Souza Júnior (1989). Foi considerada freqüência alélica igual a 0,5 . As estimativas dos parâmetros foram obtidas empregando o método dos quadrados mínimos ponderados interativos, de modo semelhante ao realizado por Souza \& Ramalho (1995).

Estimou-se a resposta correlacionada ( $\mathrm{RC}$ ) no porte (Y) pela seleção efetuada na produtividade de grãos (X), 
considerando a média das duas gerações. $\mathrm{A} \mathrm{RC}_{\mathrm{xy}}$, pela seguinte expressão (FALCONER \& MACKAY, 1996):

$$
R C_{x y}=i h_{x} h_{y} r_{x y} \sigma_{y}
$$

em que:

$i$ : intensidade de seleção padronizada;

$h_{x}$ : raiz quadrada da herdabilidade para o caráter X;

$h_{y}$ : raiz quadrada da herdabilidade para o caráter $\mathrm{Y}$;

$r_{x y}^{y}$ : correlação genética entre os caracteres X e Y. Esta por sua vez foi obtida utilizando procedimento semelhante ao apresentado por Cruz et al. (2004);

$\sigma_{y}$ : desvio padrão fenotípico médio do caráter $\mathrm{Y}$.

\section{RESULTADOS E DISCUSSÃO}

Deve ser enfatizado que quando se avança a população pelo método genealógico, a progênie é proveniente de uma planta. Assim, a quantidade de sementes na maioria das situações, limita a utilização de parcelas maiores e maior número de repetições e/ou locais na avaliação. Foi por essa razão que na avaliação das progênies $\mathrm{F}_{4: 5}$, utilizou-se parcelas de 1 metro linear. Contudo, constatou-se para essa geração que a precisão experimental foi semelhante ao que é relatado com a cultura do feijoeiro na região (AGUIAR et al., 2004; TAKEDA, 1990).

Constatou-se, na análise conjunta, que o efeito de gerações foi significativo apenas para a produção de grãos. Na geração $\mathrm{F}_{4: 6}$ a produtividade de grãos, em g/planta, foi 11,9\% acima da observada na geração $\mathrm{F}_{4: 5}$ Em ocorrendo dominância na expressão do caráter, esperava-se que na geração $\mathrm{F}_{4: 5}$ a média fosse superior à da geração $\mathrm{F}_{4: 6}$. Na ausência de dominância elas deveriam ser iguais. É preciso salientar que ao efeito de gerações está incluso também o efeito de safra. A geração $F_{4: 5}$ foi avaliada na denominada safra 'das águas', semeadura em novembro e a $F_{4: 6}$ na safra 'das secas', semeadura em fevereiro, irrigando quando necessário. Maiores produtividades médias em experimentos conduzidos na safra 'das secas' em relação à 'das águas' no sul de Minas Gerais são frequientes (SILVA et al., 2004; VALÉRIO et al., 1999). Já para nota de porte os valores médios não diferiram entre gerações. Para esse caráter era esperado que a média fosse superior na geração $\mathrm{F}_{4: 5}$. Isto porque, como já mencionado, ela foi avaliada na safra 'das águas', em que o desenvolvimento vegetativo das plantas é maior e a planta dificilmente permanece ereta. Isso não foi detectado na análise de variância, provavelmente porque as notas são atribuídas comparativamente entre as progênies em cada geração separadamente.

Foi detectada diferença significativa $(\mathrm{P} \leq 0,01)$ entre progênies. Na decomposição dessa fonte de variação, de acordo com a genealogia, para ambos os caracteres o teste de $\mathrm{F}$ foi significativo entre progênies $\mathrm{F}_{2}, \mathrm{~F}_{2: 3}$ e $\mathrm{F}_{3: 4}$, evidenciando a existência de variação genética entre as progênies avaliadas. Os genitores que deram origem à população segregante são ambos da raça Mesoamericana (SINGH et al., 1991), bem adaptados e diferindo na arquitetura da planta. Isso explica a variação genética entre as progênies observadas para ambos os caracteres.

$A$ interação gerações $x$ progênies (ExP) foi significativa $(\mathrm{P} \leq 0,01)$ apenas para o caráter produção de grãos. Contudo, decompondo a interação de acordo com a genealogia, verificou-se significância $(\mathrm{P} \leq 0,05)$ apenas para interação gerações x progênies $\mathrm{F}_{2: 3}$. A variância da interação gerações x progênies $\left(\hat{\sigma}_{E P}^{2}\right)$ foi de magnitude semelhante à variância genética entre as progênies no caso da produção de grãos. Já para nota de porte, a estimativa do componente da interação $\hat{\sigma}_{E P}^{2}$ foi praticamente nula (Tabelas 1 e 2). O relato de ocorrência de interação genótipos $\mathrm{x}$ ambientes é freqüente na literatura com a cultura do feijoeiro (AGUIAR et al., 2004; PEREIRA, 2003), o que corrobora os resultados obtidos no presente trabalho.

As estimativas dos parâmetros genéticos e fenotípicos também evidenciaram a existência de variação entre as progênies. Em todas as situações a estimativa de foi diferente de zero (Tabela 2). Observe que a herdabilidade da produtividade de grãos em ambas as gerações foi diferente de zero, evidenciando a possibilidade de sucesso com a seleção.

A estimativa de herdabilidade $\left(h^{2}\right)$ na geração $\mathrm{F}_{4: 5}$ foi inferior à observada na $\mathrm{F}_{4: 6}$. Isso ocorreu devido à menor precisão experimental nessa geração. A parcela era menor e, além disso, como a semeadura foi realizada em novembro, safra 'das águas', como já mencionado, as condições experimentais foram piores, especialmente na colheita. É oportuno enfatizar que como a contribuição de $\sigma_{D}^{2}$ foi praticamente nula para esse caráter, como será comentado posteriormente (Tabela 3 ), a estimativa de pode ser considerada no sentido restrito e envolve no numerador da expressão $1,75 \sigma_{A}^{2}$ existente entre plantas da geração $\mathrm{F}_{2}$. 
TABELA 1 - Estimativas das variâncias fenotípicas entre médias de progênies $\left(\sigma_{F}^{2}\right)$, variâncias genéticas entre progênies $\left(\sigma_{P}^{2}\right)$ e sua decomposição de acordo com a genealogia; $\hat{\sigma}_{P_{F_{2}}}^{2}$ : variância genética entre progênies derivadas de plantas $\mathrm{F}_{2} ; \hat{\sigma}_{P_{F_{2}: 3}}^{2}$ : variância genética entre progênies $\mathrm{F}_{3}$ dentro de $\mathrm{F}_{2} ; \hat{\sigma}_{P_{F_{3: 4}}}^{2}$ : variância genética entre progênies $\mathrm{F}_{4}$ dentro de $\mathrm{F}_{3} ; \hat{\sigma}_{E P}^{2}$ : variância da interação gerações x progênies; $\hat{\sigma}_{E P_{F_{2}}}^{2}$ : variância da interação gerações x progênies $\mathrm{F}_{2} ; \hat{\sigma}_{E P_{F_{2: 3}}}^{2}$ : variância da interação gerações x progênies $\mathrm{F}_{3}$ dentro de $\mathrm{F}_{2} ; \hat{\sigma}_{E P_{F_{3: 4}}}^{2}$ : variância da interação gerações $\mathrm{x}$ progênies $\mathrm{F}_{4}$ dentro de $\mathrm{F}_{3}$ e herdabilidade $\left(h^{2}\right)$ e respectivos intervalos de confiança referentes às avaliações para

\begin{tabular}{|c|c|c|c|}
\hline \multirow{2}{*}{$\begin{array}{c}\text { Produção } \\
\text { de grãos } \\
\text { (g/planta) }\end{array}$} & \multicolumn{2}{|c|}{ Gerações } & \multirow[b]{2}{*}{ Conjunta } \\
\hline & $\mathbf{F}_{4: 5}$ & $\mathbf{F}_{4: 6}$ & \\
\hline$\hat{\sigma}^{2}$ & 5,0017 & 5,2510 & 3,0994 \\
\hline $\bar{F}$ & - & - & - \\
\hline \multirow{2}{*}{$\hat{\sigma}_{P}^{2}$} & 1,4493 & 2,5176 & 1,0723 \\
\hline & $(0,7768-3,6048)^{2 /}$ & $(1,7385-3,9715)^{2 /}$ & $(0,7554-1,6415)^{2 /}$ \\
\hline \multirow{2}{*}{$\hat{\sigma}_{P_{F_{2}}}^{2}$} & 0,5164 & 0,4617 & 0,3674 \\
\hline & $(0,1657-7,1789)^{2 /}$ & $(0,1482-6,4184)^{2 /}$ & $(0,1179-5,1075)^{2 /}$ \\
\hline \multirow{2}{*}{$\hat{\sigma}_{P_{F_{2: 3}}}^{2}$} & 1,1476 & 0,5603 & 0,1299 \\
\hline & $(0,5429-3,8249)^{2 /}$ & $(0,1518-22,412)^{2 /}$ & $(0,0259-129,90)^{2 /}$ \\
\hline \multirow{2}{*}{$\hat{\sigma}_{P_{F_{3: 4}}}^{2}$} & $-0,2041$ & 1,5031 & 0,5799 \\
\hline & $(-0,2650--0,1621)^{2 /}$ & $(0,7899-3,9012)^{2 /}$ & $(0,2408-2,8121)^{2 /}$ \\
\hline \multirow[b]{2}{*}{$\hat{\sigma}_{E P}^{2}$} & & & 0,9110 \\
\hline & - & - & $(0,4448-2,8057)^{2 /}$ \\
\hline \multirow{2}{*}{$\hat{\sigma}_{E P_{F_{2}}}^{2}$} & & & 0,1218 \\
\hline & - & - & $(0,0242-121,80)^{2 /}$ \\
\hline \multirow{2}{*}{$\hat{\sigma}_{E P_{F_{2: 3}}}^{2}$} & - & - & 0,7204 \\
\hline & - & - & $0,2807-4,3335)^{2 /}$ \\
\hline \multirow[t]{2}{*}{$\hat{\sigma}_{E P_{F_{3} 4}}^{2}$} & - & - & 0,0696 \\
\hline & & & $(0,0139-69,600)^{2 /}$ \\
\hline \multirow[b]{2}{*}{$h^{2}(\%)$} & 28,98 & 47,94 & 34,58 \\
\hline & $(9,17-44,47)^{1 /}$ & $(33,42-59,30)^{1 /}$ & $(16,35-48,86)^{1 /}$ \\
\hline
\end{tabular}

1/ L.I. e L.S - limites inferiores e superiores do intervalo de confiança para $h^{2}$ com $5 \%$ de probabilidade.

2/ L.I e L.S. - limites inferiores e superiores do intervalo de confiança para as variâncias com 5\% de probabilidade. 
TABELA 2 - Estimativas das variâncias fenotípicas entre médias de progênies $\left(\sigma_{F}^{2}\right)$, variâncias genéticas entre $\operatorname{progênies}\left(\sigma_{P}^{2}\right)$ e sua decomposição de acordo com a genealogia; $\hat{\sigma}_{P_{F_{2}}}^{2}$ : variância genética entre progênies derivadas de plantas $\mathrm{F}_{2} ; \hat{\sigma}_{P_{F_{2}: 3}}^{2}$ : variância genética entre progênies $\mathrm{F}_{3}$ dentro de $\mathrm{F}_{2} ; \hat{\sigma}_{P_{F_{3}: 4}}^{2}$ : variância genética entre progênies $\mathrm{F}_{4}$ dentro de $\mathrm{F}_{3} ; \hat{\sigma}_{E P}^{2}$ : variância da interação gerações x progênies; $\hat{\sigma}_{E P_{F_{2}}}^{2}$ : variância da interação gerações x progênies $\mathrm{F}_{2} ; \hat{\sigma}_{E P_{F_{2: 3}}}^{2}$ : variância da interação gerações x progênies $\mathrm{F}_{3}$ dentro de $\mathrm{F}_{2} ; \hat{\sigma}_{E P_{F_{3: 4}}}^{2}$ : variância da interação gerações x progênies $\mathrm{F}_{4}$ dentro de $\mathrm{F}_{3}$ e herdabilidade $\left(h^{2}\right)$ e respectivos intervalos de confiança referentes às avaliações para notas de porte das progênies nas gerações $\mathrm{F}_{4: 5}, \mathrm{~F}_{4: 6}$ e à análise conjunta das mesmas.

\begin{tabular}{|c|c|c|c|}
\hline \multirow{2}{*}{$\begin{array}{l}\text { Notas de } \\
\text { porte }\end{array}$} & \multicolumn{2}{|c|}{ Gerações } & \multirow{2}{*}{ Conjunta } \\
\hline & $\mathbf{F}_{4: 5}$ & $\mathbf{F}_{4: 6}$ & \\
\hline$\hat{\sigma}_{-}^{2}$ & 0,3845 & 0,2024 & 0,2037 \\
\hline $\bar{F}$ & - & - & - \\
\hline \multirow{2}{*}{$\hat{\sigma}_{P}^{2}$} & 0,1576 & 0,0835 & 0,1139 \\
\hline & $(0,1165-0,2786)^{2 /}$ & $(0,0540-0,1461)^{2 /}$ & $(0,0850-0,1606)^{2 /}$ \\
\hline \multirow{2}{*}{$\hat{\sigma}_{P_{F_{2}}}^{2}$} & 0,1460 & 0,0674 & 0,0725 \\
\hline & $(0,0905-0,2742)^{2 /}$ & $(0,0395-0,1406)^{2 /}$ & $(0,04139-0,1586)^{2 /}$ \\
\hline \multirow{2}{*}{$\hat{\sigma}_{P_{F_{2,3}}}^{2}$} & 0,0376 & 0,0341 & 0,0137 \\
\hline & $(0,01350-0,3105)^{2 /}$ & $(0,0161-0,1137)^{2 /}$ & $(0,0037-0,5480)^{2 /}$ \\
\hline \multirow{2}{*}{$\hat{\sigma}_{P_{F_{3: 4}}}^{2}$} & $-0,0241$ & 0,0171 & 0,0297 \\
\hline & $(-0,0313--0,0191)^{2 /}$ & $(0,0046-0,6840)^{2 /}$ & $(0,0141-0,0989)^{2 /}$ \\
\hline \multirow[t]{2}{*}{$\hat{\sigma}_{E P}^{2}$} & - & - & 0,0067 \\
\hline & & & $(0,0013-6,700)^{2 /}$ \\
\hline \multirow{2}{*}{$\hat{\sigma}_{E P_{F_{2}}}^{2}$} & - & - & 0,0342 \\
\hline & & & $(0,0167-0,1053)^{2 /}$ \\
\hline \multirow[t]{2}{*}{$\hat{\sigma}_{E P_{F_{2: 3}}}^{2}$} & - & - & 0,0232 \\
\hline & & & $(0,0083-0,1916)^{2 /}$ \\
\hline \multirow{2}{*}{$\hat{\sigma}_{E P_{F_{3: 4}}}^{2}$} & & & $-0,0493$ \\
\hline & - & - & $(-0,1424--0,0218)^{2 /}$ \\
\hline \multirow{2}{*}{$h^{2}(\%)$} & 40,99 & 41,26 & 55,92 \\
\hline & $(24,54-53,87)^{1 /}$ & $(24,90-54,09)^{1 /}$ & $(43,60-65,52)^{1 /}$ \\
\hline
\end{tabular}

1/ L.I. e L.S - limites inferiores e superiores do intervalo de confiança para $h^{2}$ com $5 \%$ de probabilidade.

2/ L.I e L.S. - limites inferiores e superiores do intervalo de confiança para as variâncias com 5\% de probabilidade. 
TABELA 3 - Estimativas dos componentes da variância genética e ambiental, com os respectivos limites inferiores e superiores e coeficientes de determinação da produção de grãos (g/parcela) e porte das plantas.

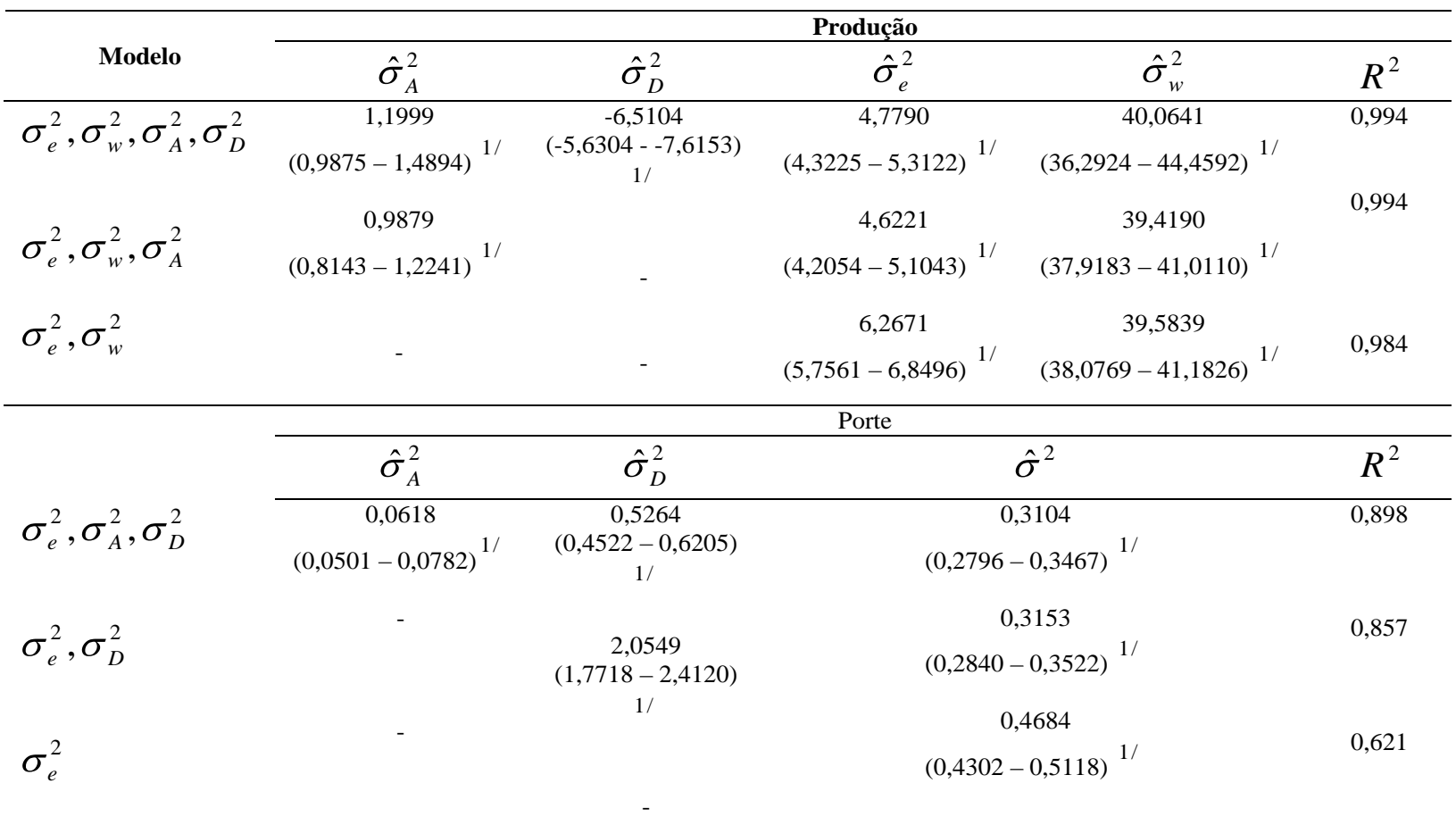

1/ L.I. e L.S. - limites inferiores e superiores do intervalo de confiança das estimativas dos componentes da variância fenotípica com $5 \%$ de probabilidade.

No caso das notas de porte, a estimativa de herdabilidade $\left(h^{2}\right)$ entre gerações e na análise conjunta foram semelhantes e também evidenciam a possibilidade de sucesso com a seleção (Tabela 2). Como para esse caráter as estimativas de herdabilidade $\left(h^{2}\right)$ foram ligeiramente superiores à herdabilidade da produtividade de grãos, provavelmente o ambiente tenha menor influência na manifestação desse caráter, como já comentado. Deve ser mencionado que como $\sigma_{D}^{2}$ foi expressivo na nota de porte (Tabela 3), a herdabilidade ( $h^{2}$ ) não pode ser considerada de sentido restrito. Resultados semelhantes às estimativas da herdabilidade para este caráter foram evidenciados por Cunha (2005) e Teixeira et al. (1999).

A contribuição da variância genética aditiva $\left(\sigma_{A}^{2}\right)$; variância de dominância $\left(\sigma_{D}^{2}\right)$; variância ambiental entre parcelas $\left(\sigma_{e}^{2}\right)$ e variância ambiental dentro das parcelas $\left(\sigma_{w}^{2}\right)$ para a variação fenotípica total da produção de grãos é mostrada na Tabela 3. Para produção de grãos a contribuição de $\sigma_{e}^{2}$ e $\sigma_{w}^{2}$ é superior a $\sigma_{A}^{2}$, e a estimativa de $\sigma_{D}^{2}$ foi nula. Observou-se que a contribuição da variação ambiental dentro da parcela $\left(\sigma_{w}^{2}\right)$ foi 8,38 vezes superior à variância ambiental entre parcelas $\left(\sigma_{e}^{2}\right)$ (Tabela 3). Esse fato evidencia que o erro é mais acentuado dentro do que entre as parcelas. Existem poucas referências a esse respeito na literatura. Souza \& Ramalho (1995), trabalhando com a cultura do feijoeiro, verificaram que para produção de grãos, a variância ambiental dentro das parcelas foi praticamente nula. Na cultura do milho, a relação entre a variância ambiental dentro da parcela é superior à variância entre parcelas em magnitude semelhante à observada nesse 
trabalho com a cultura do feijoeiro (PACHECO, 1987). A variância ambiental dentro das parcelas depende de alguns fatores, a maioria deles que podem ser manuseados pelos melhoristas, entre eles: melhor distribuição das sementes, dos fertilizantes, da água de irrigação quando for o caso, e obter estande o mais uniforme possível. Esse melhor manejo certamente deverá melhorar a precisão experimental e o sucesso com a seleção.

A predominância dos efeitos aditivos no controle genético da produtividade de grãos tem sido relatada em várias oportunidades (ABREU, 1989; TAKEDA, 1990; VIZGARRA, 1991); contudo, há relatos também da ocorrência de dominância (CHUNG \& STEVENSON, 1973; FOOLAD \& BASSARI, 1983).

Com as notas de porte não foram obtidos os dados por planta; nesse caso, $\sigma_{e}^{2}$ e $\sigma_{w}^{2}$ se confundem, sendo representados por $\sigma^{2}$. A contribuição de $\sigma_{D}^{2}$ foi superior a $\sigma_{A}^{2}$ e também a $\sigma^{2}$, permitindo inferir que para esse caráter a contribuição da variância de dominância foi expressiva (Tabela 3). Há inconsistência na literatura a respeito da ocorrência de dominância para este caráter. Teixeira et al. (1999), estudando o controle genético do porte na cultura do feijoeiro, constataram a predominância do efeito aditivo no cruzamento das cultivares Carioca MG x H4, ao passo que no cruzamento das cultivares Carioca $\mathrm{x}$ FT-Tarumã, os efeitos de dominância prevaleceram.

A resposta correlacionada no porte pela seleção efetuada na produtividade foi de $R C_{x y}=0,1778$, ou seja, $5,96 \%$ da média do porte. Ficou assim evidenciado que a seleção efetuada apenas considerando a produtividade de grãos contribui para obtenção de plantas menos eretas, maiores notas, o que é prejudicial. Contudo, a estimativa da correlação genética foi de pequena magnitude $\left(r_{x y}=\right.$ 0,32). Resultado semelhante foi obtido por Collicchio et al. (1997). Desse modo, será possível selecionar plantas que sejam produtivas e também com porte aceitável. Para isso, a melhor opção é utilizar algum índice de seleção como relatado em algumas publicações (CRUZ et al., 2004; FALCONER \& MACKAY, 1996).

\section{CONCLUSÕES}

Constatou-se que na produção de grãos por planta, a variância ambiental dentro da parcela foi o principal componente da variância fenotípica entre progênies. A variância genética aditiva foi predominante para a produção de grãos e a variância de dominância foi expressiva para as notas de porte.

\section{REFERÊNCIAS BIBLIOGRÁFICAS}

ABREU, A. de F. B. Avaliação de progênies de feijoeiro do cruzamento 'Carioca 80' $x$ 'Rio Tibagil em diferentes densidades de plantio. 1989. 63 f. Dissertação (Mestrado em Genética e Melhoramento de Plantas) - Escola Superior de Agricultura de Lavras, Lavras, 1989.

AGUIAR, M. S. de; RAMALHO, M. A. P.; ABREU, A. F. B. T.; CARNEIRO, J. E. de S. Effect of the number of intermatings on genetic properties of a segregant common bean population. Crop breeding and applied biotechnology, Londrina, v. 4, n. 2, p. 234-240, Apr./June 2004.

CHUNG, J. H.; STEVENSON, E. Diallel analiyses of the genetic variation in some quantitative characters in dry beans. New Zealand Journal of Agricultural Research, Wellington, v. 16, n. 2, p. 223-231, May 1973.

COLLICCHIO, E.; RAMALHO, M. A. P.; ABREU, A. F. B. Associação entre o porte da planta do feijoeiro e o tamanho dos grãos. Pesquisa Agropecuária Brasileira, Brasília, v. 32, n. 3, p. 297-304, mar. 1997.

CRUZ, C. D.; REGAZZI, A. J.; CARNEIRO, P. C. S. Modelos biométricos aplicados as melhoramento genético. 3. ed. Viçosa: UFV, 2004. v. 1, 480 p.

CUNHA, W. G. Seleção recorrente em feijão do tipo carioca para porte ereto. 2005. 52 p. Dissertação (Mestrado em Genética e Melhoramento de Plantas) - Universidade Federal de Lavras, Lavras, 2005.

FALCONER, D. S.; MACKAY, T. F. Introduction to quantitative genetics. Malaysia: Longman, 1996. 463 p.

FOOLAD, M. R.; BASSIRI, A. Estimates of combining ability, reciprocal effects and heterosis for yield and yield components in a common bean diallel cross. The Journal of Agricultural Science, Cambridge, v. 100, n. 1, p. 103108, Feb. 1983.

KNAPP, S. J.; STROUP, W. W.; ROSS, W. M. Exact condidence intervals for heriability on a progeny mean basis. Crop Science, Madison, v. 25, n. 1, p. 192-194, Jan./ Feb. 1985.

OTUBO, S. T.; RAMALHO, M. A. P.; ABREU, A. F. B.; SANTOS, J. B. Genetic control of low temperature tolerance in germination if the common bean (Phaseolus Vulgaris L.). Euphytica, Wageningen, v. 89, n. 3, p. 313-317, 1995. 
PACHECO, C. A. P. Avaliação de progênies de meios irmãos da população de milho $\mathbf{c m s} \mathbf{- 3 9}$ em diferentes condições de ambiente: 2 ciclo de seleção. 1987. Dissertação (Mestrado em Agronomia (Genética e Melhoramento de Plantas) Universidade Federal de Lavras, Lavras, 1987.

PEREIRA, H. S. Seleção de linhagens de feijão tipo Carioca com pirâmide de alelos de resistência à antracnose e outros fenótipos favoráveis. 2003. 78 p. Dissertação (Mestrado em Genética e Melhoramento de Plantas) - Universidade Federal de Lavras, Lavras, 2003.

RAMALHO, M. A. P.; FERREIRA, D. F.; OLIVEIRA, A. C. Experimentação em genética e melhoramento de plantas. 2. ed. Lavras: UFLA, 2005. 326 p.

RAMALHO, M. A. P.; SANTOS, J. B.; ZIMMERMANN, M. J. O. Genética quantitativa em plantas autógamas: aplicações ao melhoramento do feijoeiro. Goiânia: UFG, 1993. $271 \mathrm{p}$.

SANTOS, J. B. Controle genético de caracteres agronômicos e potencialidades de cultivares de feijão (Phaseolus vulgaris L.) para o melhoramento genético. 1984. 223 f. Tese (Doutorado) - Escola Superior de Agricultura Luiz de Queiroz, Piracicaba, 1984.

SILVA, N. O.; RAMALHO, M. A. P.; ABREU, A. B. F.; CARNEIRO, J. E. de S. Performance of common bean families after different generations under natural selection. Genetics and Molecular Biology, Ribeirão Preto, v. 27, n. 4, p. 574-578, Dec. 2004.

SINGH, S. P.; GEPTS, P.; DEBOUCK, D. G. Races of common bean (Phaseolus vulgaris L.). Economic Botany, Bronx, v. 45, n. 3, p. 379-396, July/Sept. 1991.

SOUZA, E. A.; RAMALHO, M. A. P. Estimates of genetic and phenotypic variance of some traits of dry bean using a segregant population from the cross Jalo $\mathrm{x}$ Small White. Revista Brasileira de Genética, Ribeirão Preto, v. 18, n. 1, p. 87-91, Mar. 1995.

SOUZA JÚNIOR, C. L. Componentes da variância genética e suas implicações no melhoramento vegetal. Piracicaba: FEALQ, 1989. 134 p.

TAKEDA, C. Avaliação de progenies de feijoeiro do cruzamento ESAL 501 x A 354 em diferentes ambientes. 1990. 82 f. Dissertação (Mestrado) - Escola Superior de Agricultura de Lavras, Lavras, 1990.

TEIXEIRA, F. F.; RAMALHO, M. A. P.; ABREU, A. F. B. Genetic control of plant architecture in the common bean (Phaseolus vulgaris L.). Genetics and Molecular Biology, Ribeirão Preto, v. 22, n. 4, p. 577-582, Dec. 1999.

VALÉRIO, C. R.; ANDRADE, M. J. B.; FERREIRA, D. F. Comportamento das cultivares de feijão Aporé, Carioca e Pérola em diferentes populações de plantas e espaçamento entre linhas. Ciência e Agrotecnologia, Lavras, v. 23, n. 3, p. 515-528, jul./set. 1999.

VIZGARRA, O. N. Capacidade de combinação de algumas cultivares de feijoeiro com diferentes mecanismos de resistência ao vírus do mosaico dourado. 1991. $78 \mathrm{f}$. Dissertação (Mestrado) - Escola Superior de Agricultura de Lavras, Lavras, 1991. 